\title{
Evaluation of the Introduction History and Genetic Diversity of Serially Introduced Fish Populations in New Zealand
}

\section{KM Purcell \& CA Stockwell \\ Department of Biological Sciences \\ North Dakota Sate University}




\section{Consequences of Invasion}

- Founding events or introductions:

- Reduced N

- Increased $\boldsymbol{F}_{I S}$

- Genetic drift

- Overall loss of genetic variation

- higher extinction rates

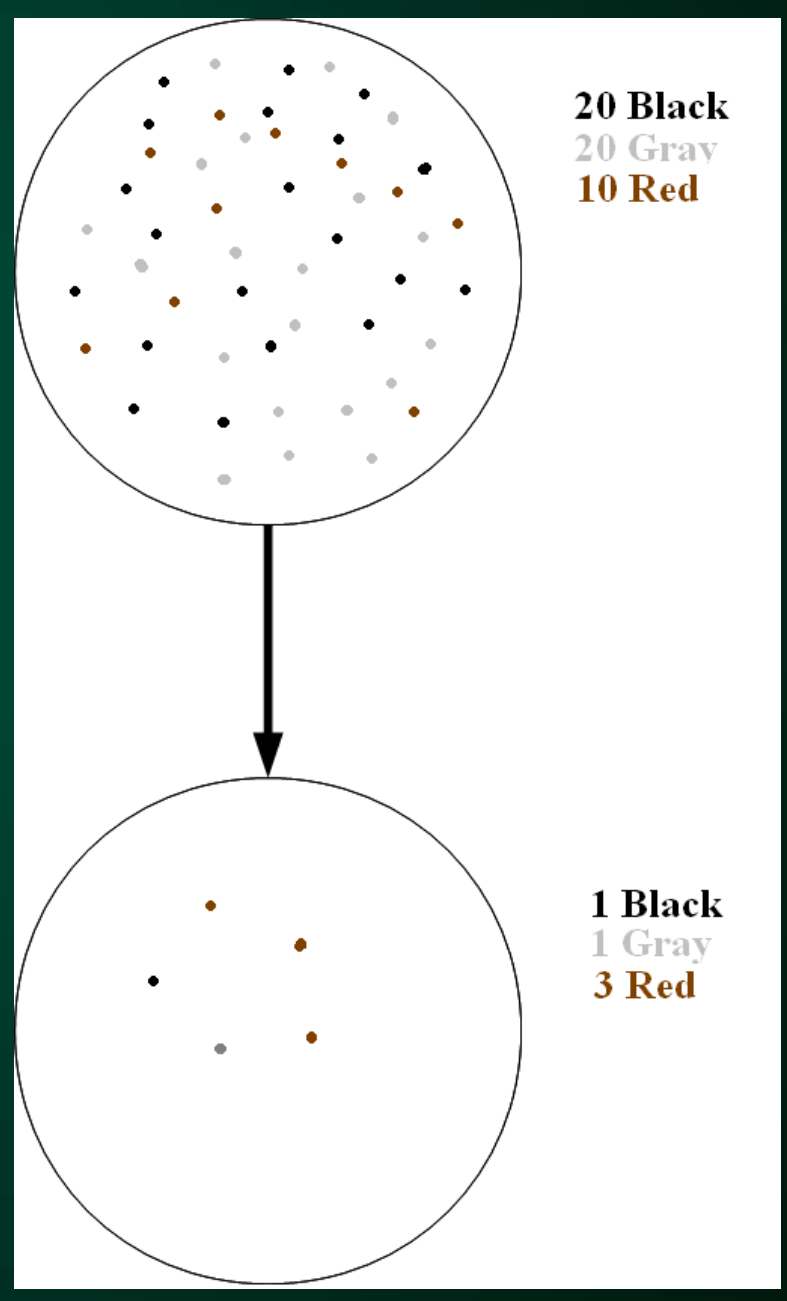




\section{"Paradox" of Invasion}

- Founding populations tend to have:

- Low genetic diversity

- Low evolutionary potential

- Low reproductive fitness

- BUT,

- Introduced populations often evolve (Reznick \& Ghalambor 2001; Stockwell et al. 2003)

NDSU NORT SARTETAREATY 


\section{"Paradox" of Invasion}

\section{Success with}

\section{Admixture}

- Cuban Lizard Example

- Kolbe et al. 2004; 2008

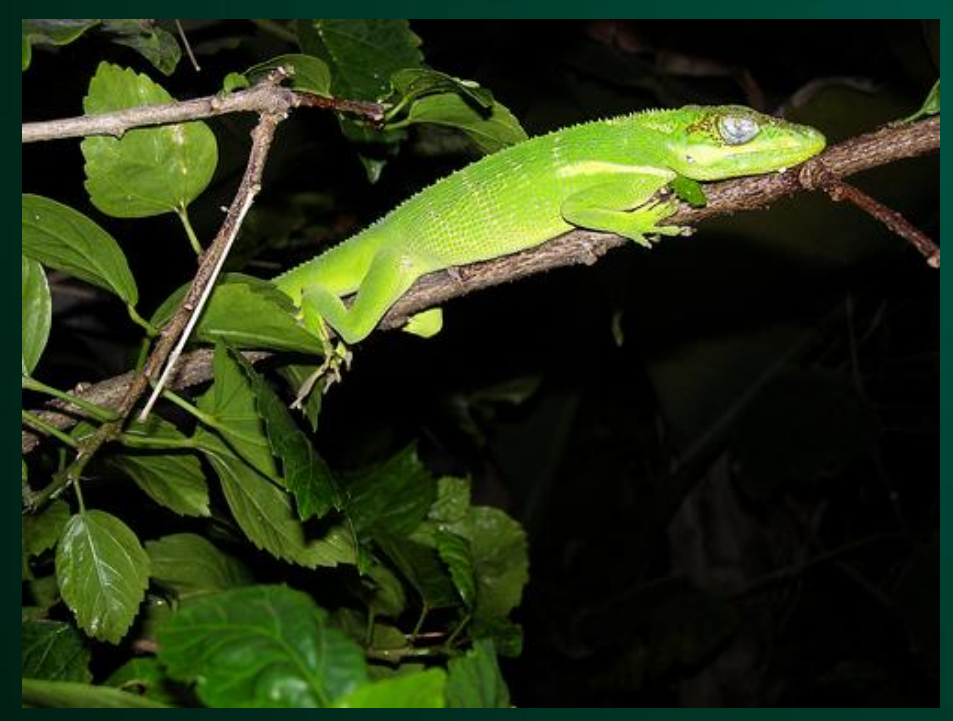

NDSU NORTH DAKOTA disadvantage

- Roman \& Darling 2007

- Brooks \& Endler 2001

- Stockwell \& Weeks 1999 


\section{Western mosquitofish Gambusia affinis}

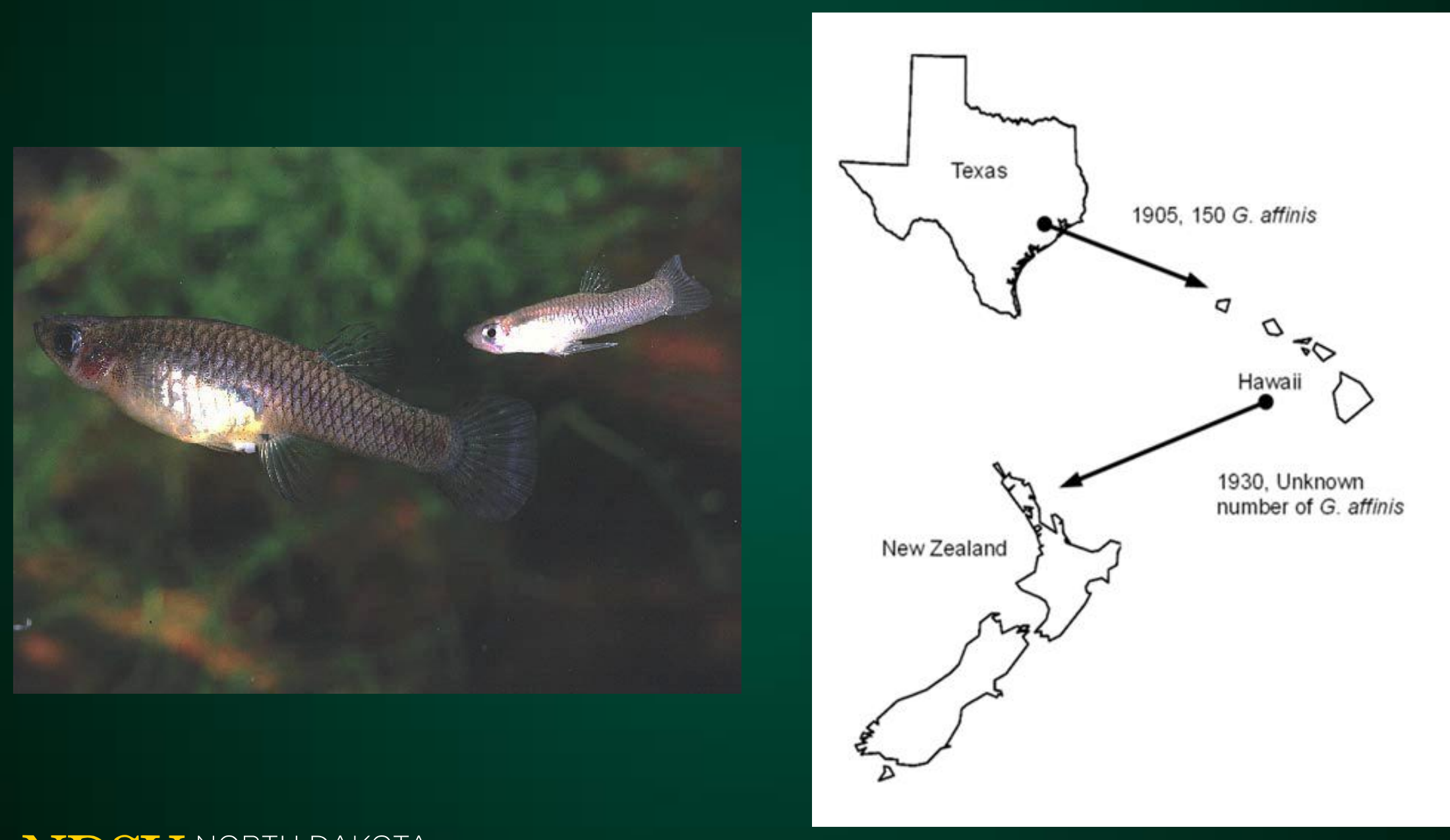

NDSU NORTHEAKOTA 


\section{Hawailan "Beach Head"}

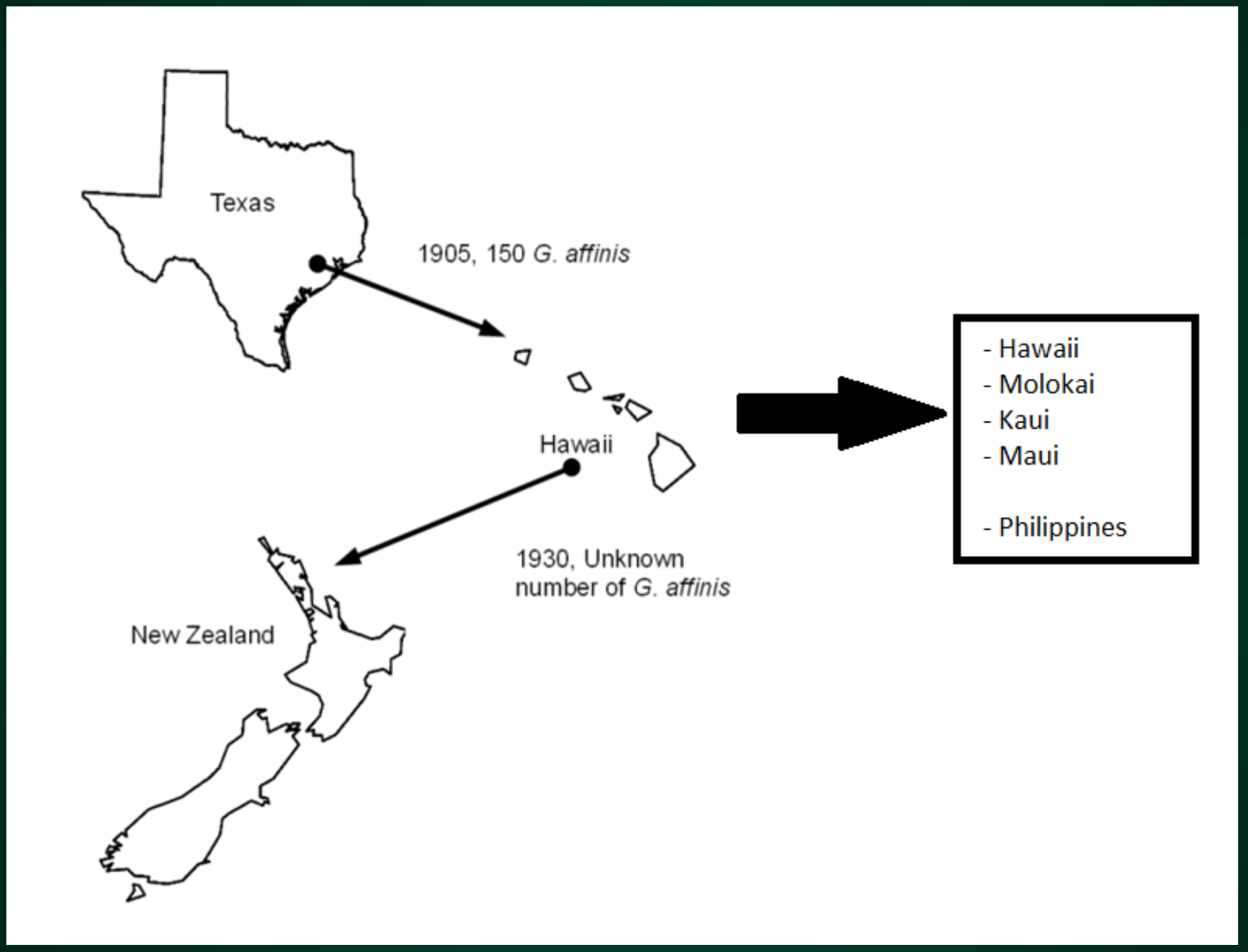

NDSU NORTH DAKOTA 


\section{Texas to Hawail Translocation}

- Scribner et al. 1992

- Increased

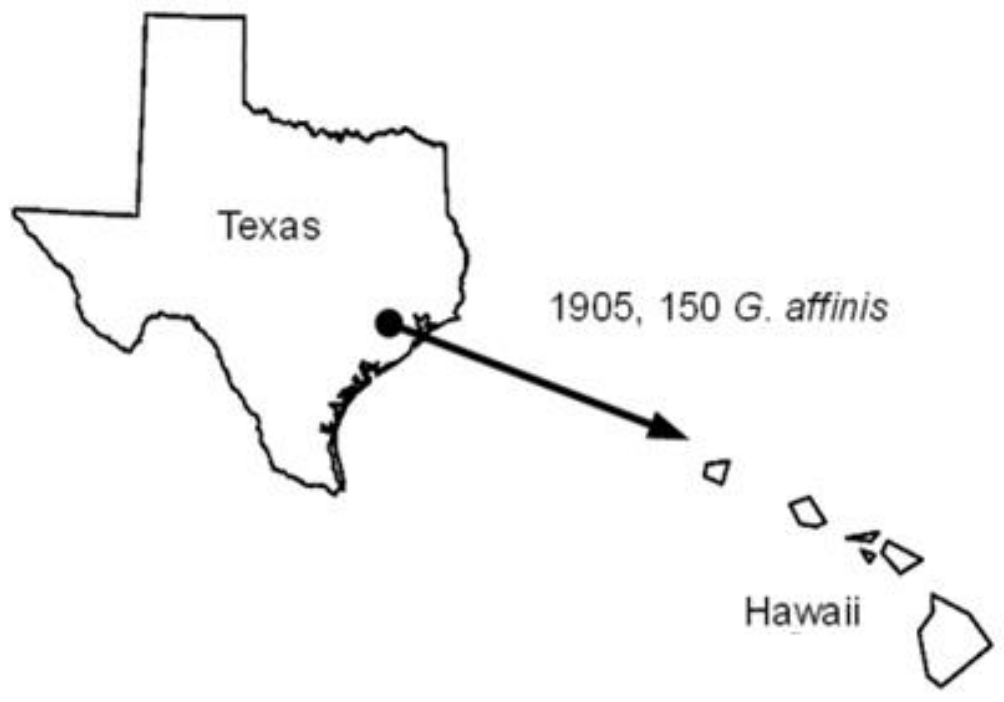
heterozygosity

- Little or no loss of allelic richness. 


\section{Questions}

- Concordance of genetic data and published record?

- Genetic impacts of serial introductions on this invasive fish species?

\section{Methods}

- Microsatellite assay - 9 loci

- Five sample locations

- 30 Individuals / sample 


\section{Map}
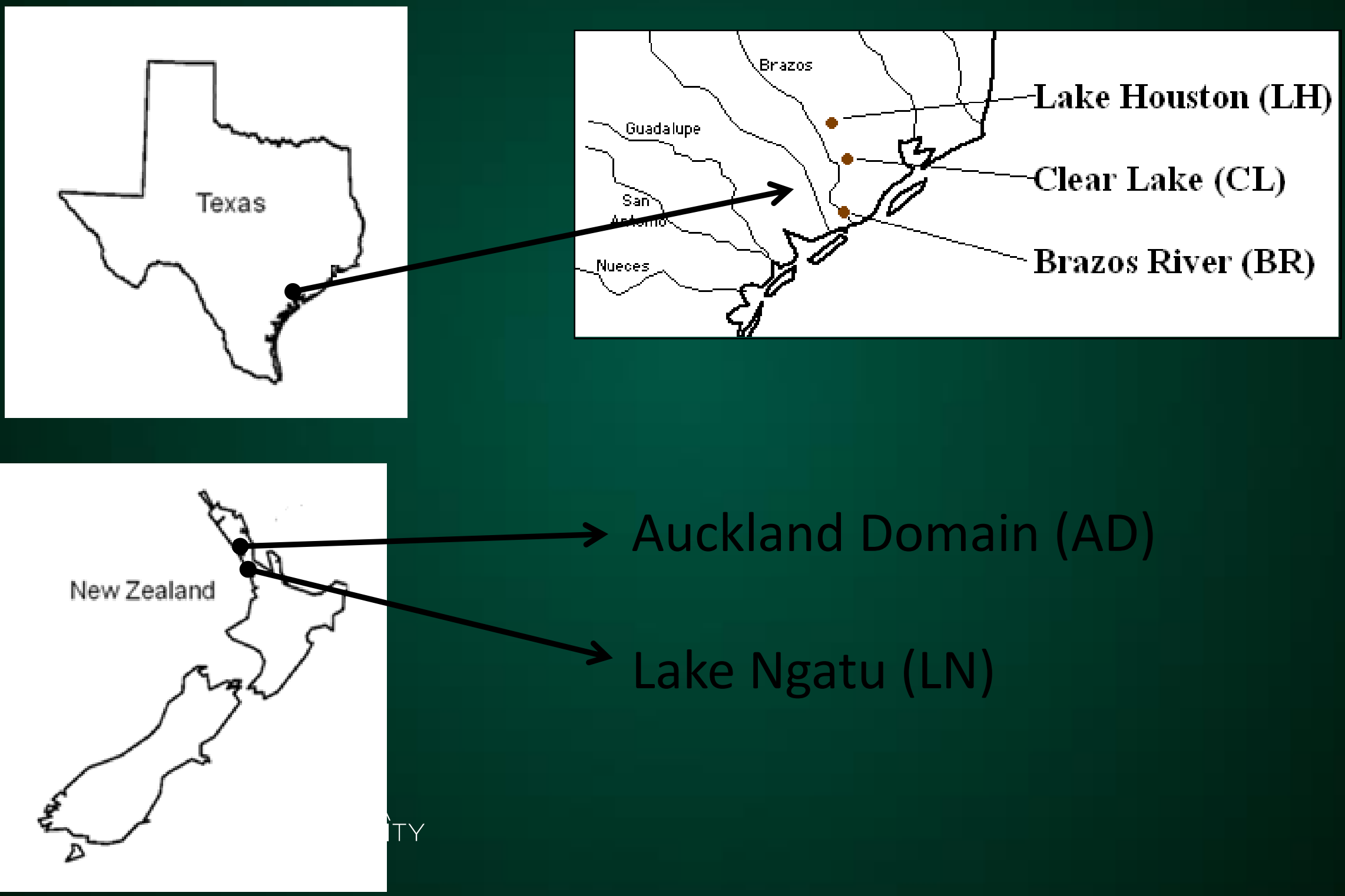

Auckland Domain (AD)

Lake Ngatu (LN) 


\section{Genetic Diversity}
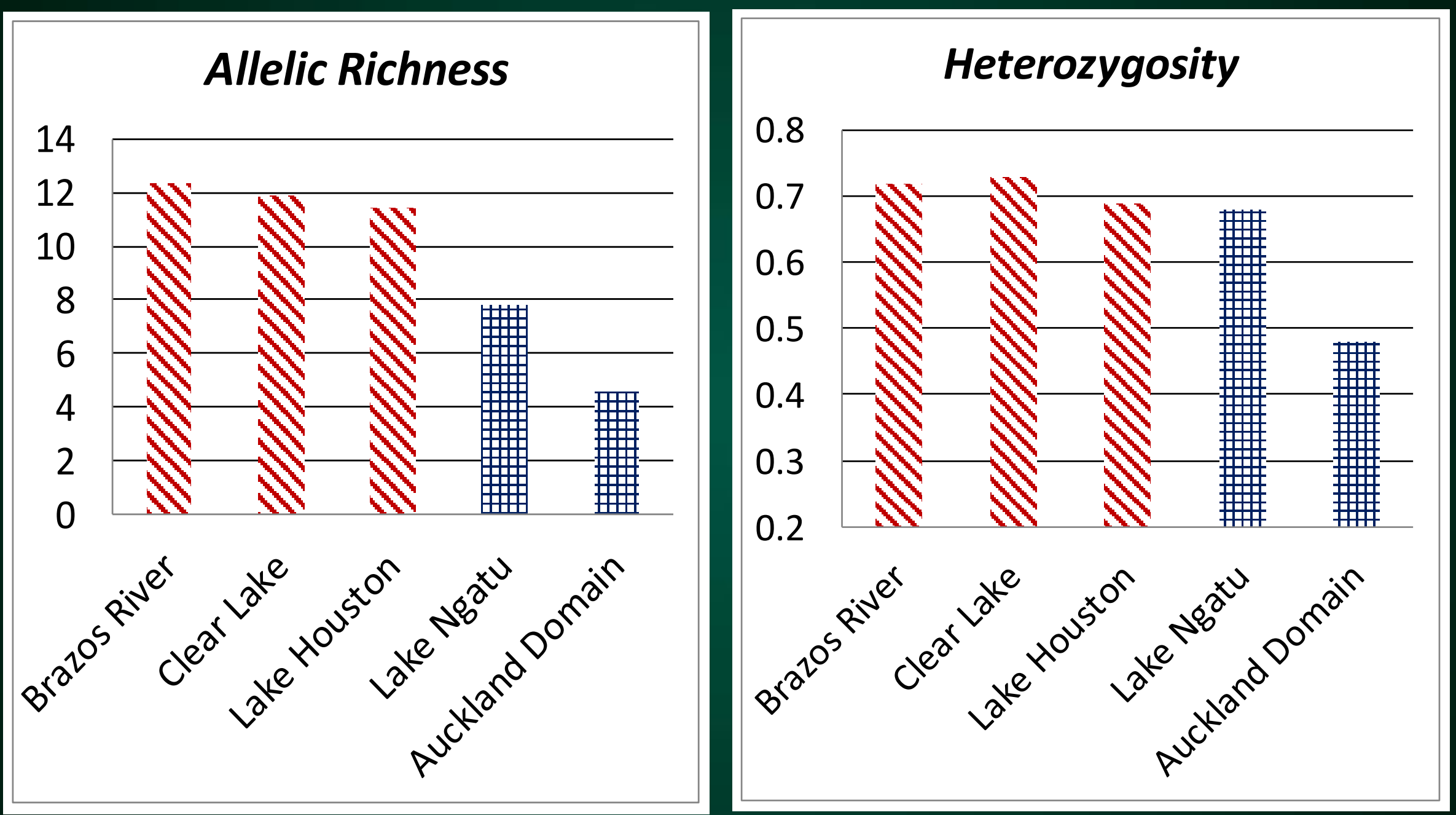

NDSU NORTH DAKOTA 


\section{Divergence estimates}

- Overall $F_{S T}=0.096$

\begin{tabular}{|c|c|c|c|c|c|}
\hline & BR, TX & CL, TX & LH, TX & LN, TX & AD, TX \\
\hline BR, TX & - & 0.009 & 0.009 & 0.091 & 0.209 \\
\hline CL, TX & $1 / 2$ & - & 0.002 & 0.078 & 0.203 \\
\hline LH, TX & $0 / 1$ & $1 / 2$ & - & 0.084 & 0.214 \\
\hline LN, NZ & $9 / 9$ & $8 / 8$ & $8 / 8$ & - & 0.088 \\
\hline AD, NZ & $9 / 9$ & $9 / 9$ & $9 / 9$ & $8 / 9$ & - \\
\hline
\end{tabular}




\section{Genetic Distance}
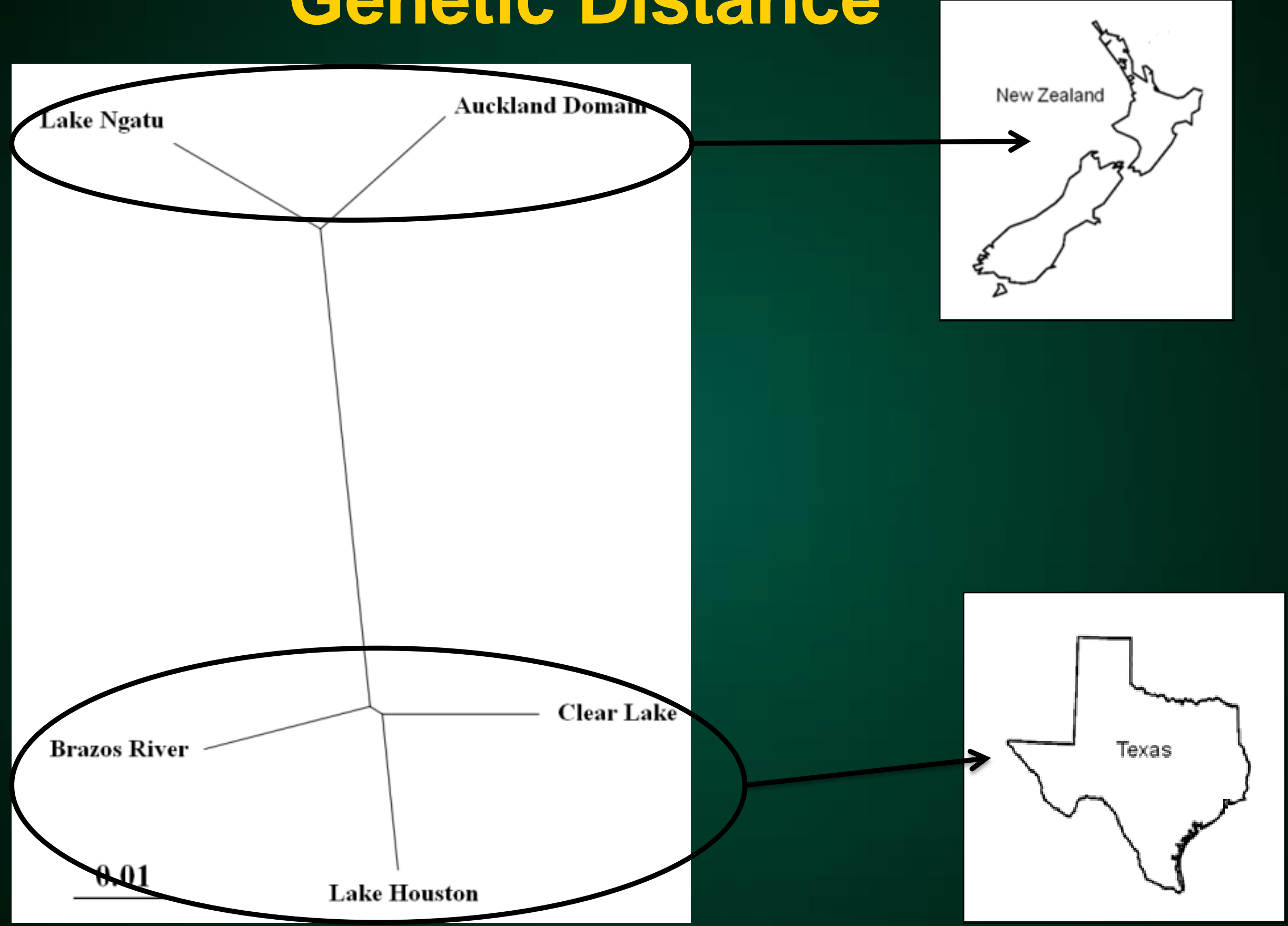


\section{Genetic Structure}

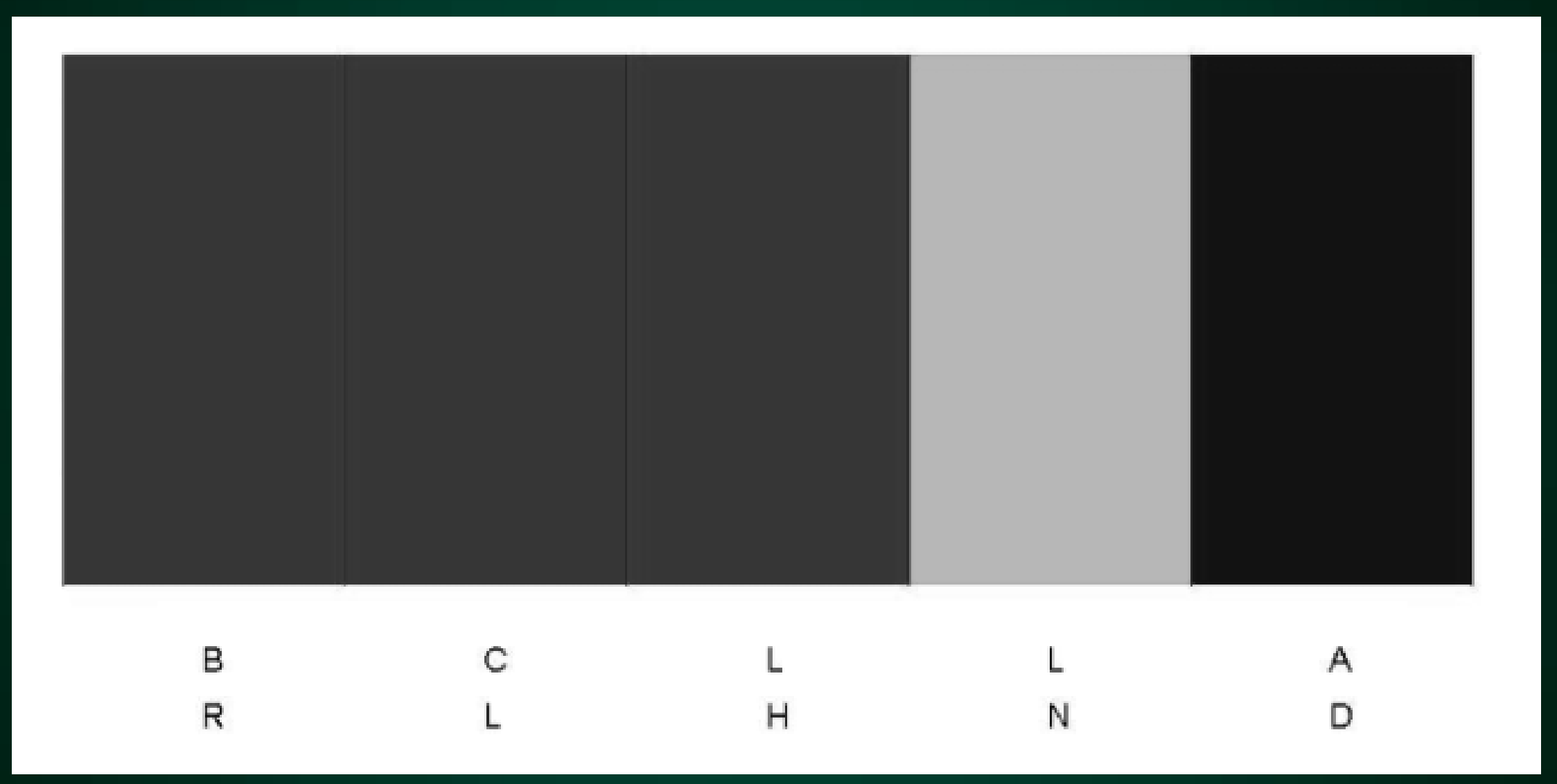

NDSU NORTH DAKOTA 


\section{Approximate Bayesian Computation}

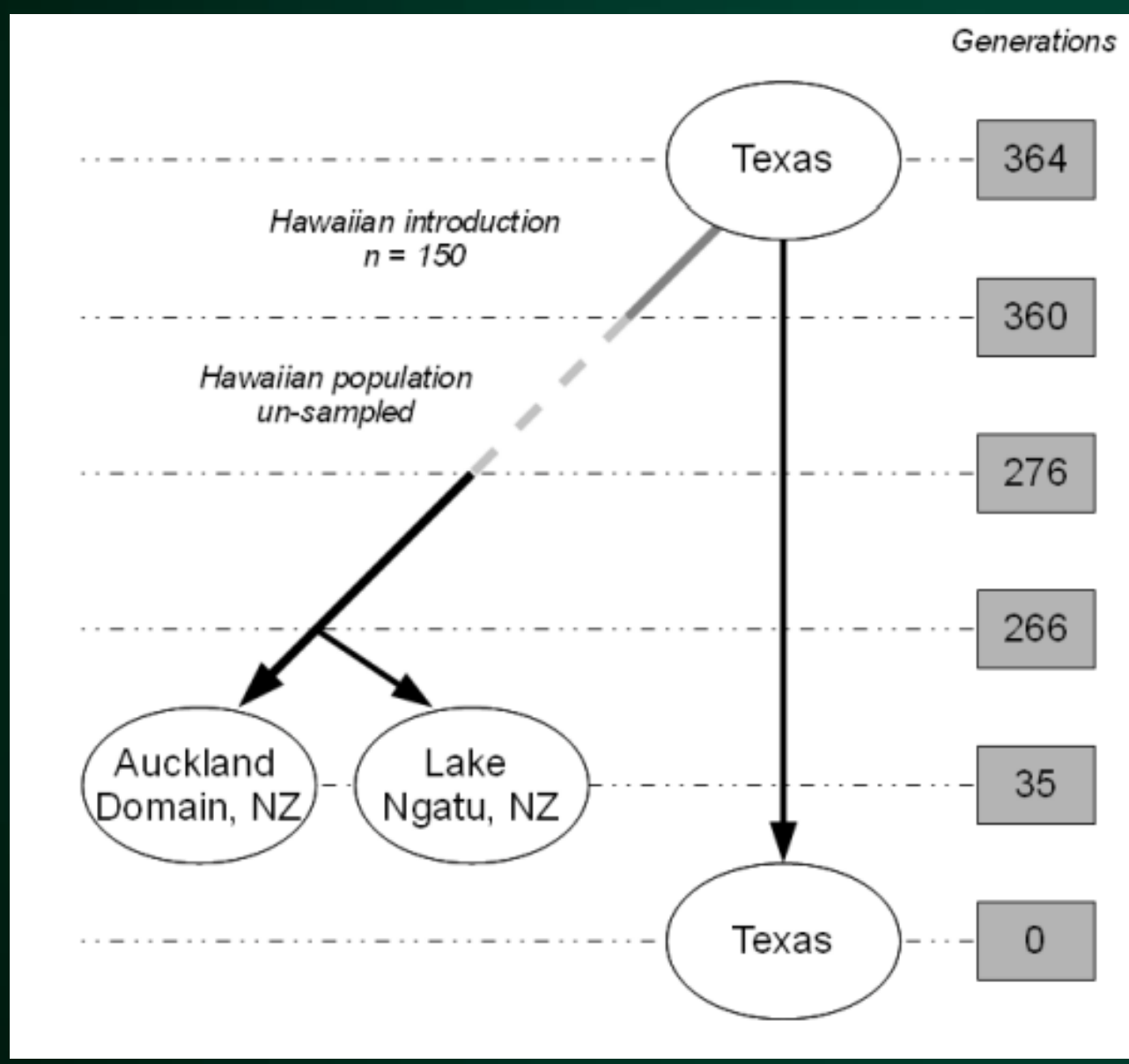

NDSU STRRTE DAKOTATIT 


\section{Approximate Bayesian Computation}
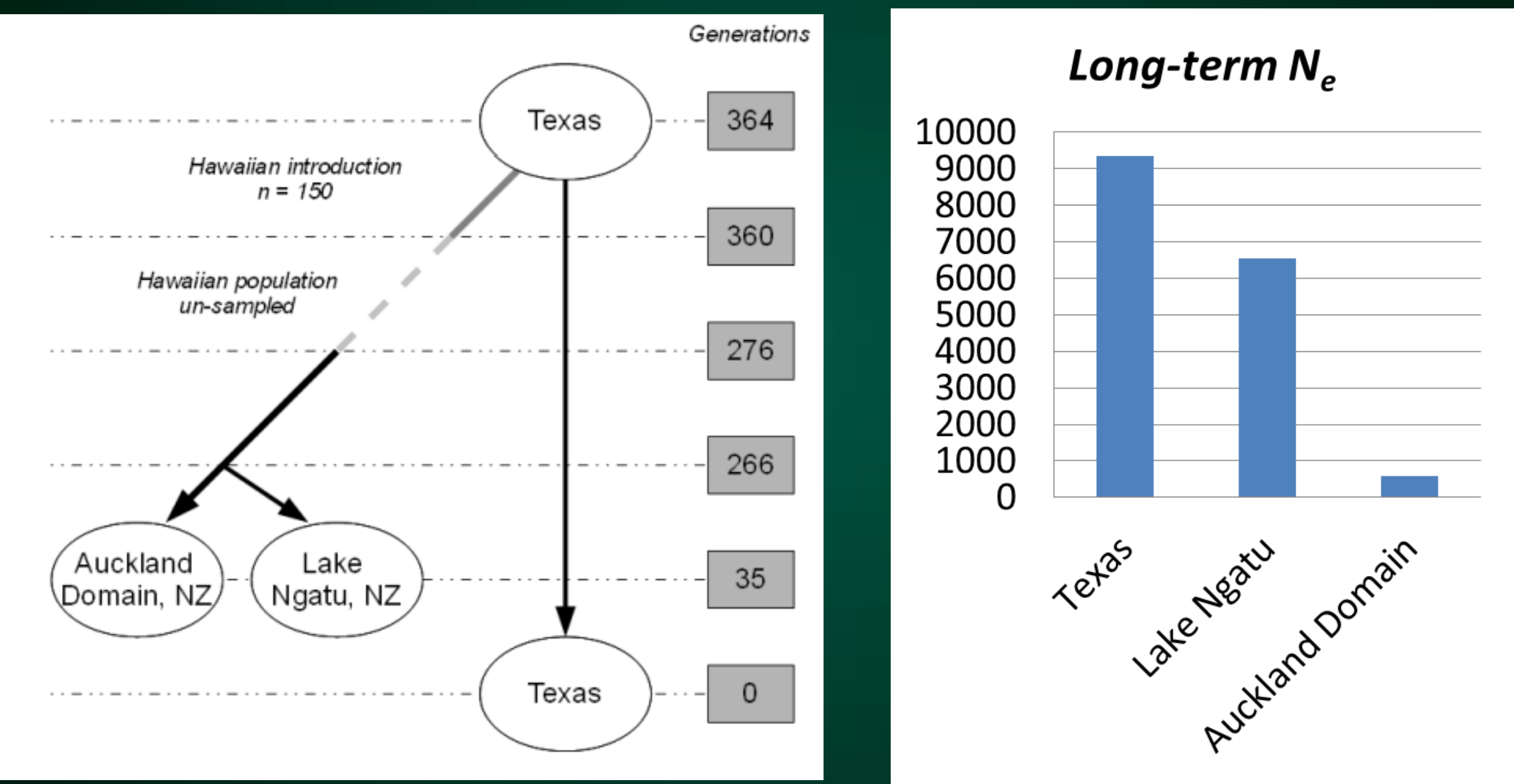

NDSU NORTH DAKOTA 


\section{Conclusions}

- Support for the documented introduction history

- Strong evidence of founder effects

- Large, persistent populations

- Reduced genetic diversity has not impacted long term population persistence.

\section{Next Step?}




\section{Acknowledgements}

NDSU Environmental and Conservation Sciences Postdoctoral Fellowship

\section{ND EPSCoR NSF Grant}

NDSU President's Travel Grant

Jan Terfehr, Nick Ling, S. Martin 


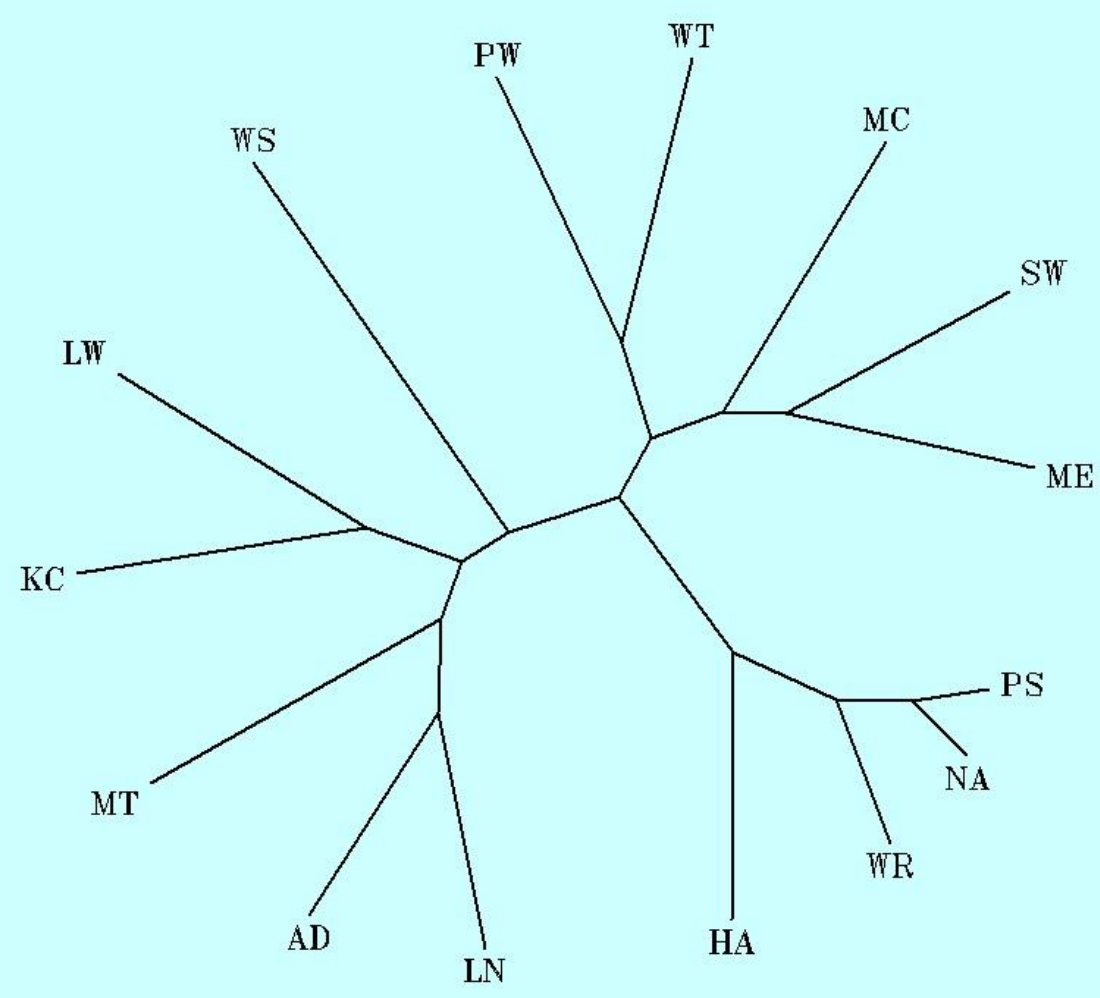

NDSU NORTHEAKOTA 